\title{
Prevenção referente às modalidades alternativas de transmissão do Trypanosoma cruzi no Brasil
}

\author{
Prevention concerning the different alternative \\ routes for transmission of Trypanosoma cruzi in Brazil
}

\author{
João Carlos Pinto Dias* e Vicente Amato Neto**
}

\begin{abstract}
RESUMO
Consideram-se habituais em doença de Chagas humana os mecanismos vetorial, transfusional e congênito de transmissão. Acidental, oral e por transplantes são ditos alternativos. Possibilidades como por outros vetores, sexual, criminal e por secreção de marsupiais são consideradas excepcionais. A prevenção dos mecanismos alternativos, incluindo o congênito, está hoje consensuada: Transmissão congênita: detecção precoce do caso e seu tratamento específico. Se possível começar, no pré-natal com sorologia de gestantes. Quando viável, pesquisar parasitologicamente o RN de mães reagentes, tratando-se imediatamente os que resultarem positivos. Sendo negativos, sorologia convencional aos 8 meses de vida, tratando imediatamente os que estiverem reagentes. Transmissão acidental: Usar treinamento e equipamentos de proteção. Se acidente, desinfecção local, sorologia convencional e inicio de tratamento específico por dez dias. Revisão da sorologia em 30 dias, seguindo-se o tratamento até a dose total, no caso de reação positiva. Transplantes de órgãos: sorologia prévia no doador e receptor. Sendo o primeiro positivo e o segundo negativo, evitar o transplante ou tratar especificamente o doador por 10 dias antes da cirurgia e o receptor nos dez dias subsequentes à mesma. Transmissão oral: de modo geral, higiene alimentar e cozimento de carnes de possíveis reservatórios. Hoje se recomenda a detecção precoce e tratamento imediato do caso, com intensa busca ativa entre os circunstantes mais próximos do paciente.
\end{abstract}

Palavras-chaves: Doença de Chagas. Mecanismos alternativos de transmissão. Controle.

\begin{abstract}
Vectorial, transfusion and congenital are considered the main transmission mechanisms in human Chagas disease. Alternative mechanisms are accidental, oral and by organ transplantation. Other hypothetic mechanisms could be by other vectors, sexual, criminal and by means of marsupial anal secretions. The present accorded strategies for prevention are: Congenital: early case detection and immediate treatment. If possible, start during the pre natal period, throughout mothers serology, performing parasitological tests in the new born from positive women. For positive cases, immediate treatment; for those negative babies, conventional serology at the $8^{\text {th }}$ month, treating specifically those with positive results. Accidental transmission: Rigorous training and utilization of protection equipments. IF accident occurs, immediate disinfection, conventional serology and beginning of specific treatment by ten days. Revision of the serology after 30 days: if positive, extend the treatment until the total dose (60 days or more). Organ transplantation: previous serology for donor and receptor. When the former is infected and the last negative, cancel the surgery or install the specific treatment by ten days before the surgery for the donor, followed by the receptor during ten days after the transplantation. Oral transmission: Specific measures are not available, food hygiene is recommended, including the cooking of meats delivered from possible reservoirs. Nowadays, the detection and immediate treatment of the case is recommended, followed by active research of new cases around the detected one.
\end{abstract}

Key-words: Chagas disease. Alternative transmission mechanisms. Control.

As formas básicas de transmissão da doença de Chagas humana $(\mathrm{DCH})$ correspondem à contaminação pelo vetor, à transmissão pela transfusão de sangue e à via congênita. Consideram-se alternativas as demais vias descritas como a via oral, por transplantes de órgãos e via acidental. São entendidas como excepcionais ou hipotéticas outras possibilidades como por via sexual, por contaminação através de outros vetores e por práticas esdrúxulas (juras de amor, uso comunitário de drogas injetáveis $)^{1,2,3}$. Com os avanços no controle dos vetores domiciliados e rigorosa seleção de doadores em toda a área endêmica, as vias alternativas cresceram de importância. Inclusive, pelos fenômenos de globalização e migrações

*Pesquisador do Instituto René Rachou, Fundação Oswaldo Cruz e Membro da Academia Mineira de Medicina, Belo Horizonte, MG. ${ }^{* *}$ Professor Emérito da Faculdade de Medicina, Universidade de São Paulo, São Paulo, SP. Ex-Secretário Estadual da Saúde de São Paulo, São Paulo, SP.

Endereço para correspondência: Dr. João Carlos Pinto Dias. CPqRR/FIOCRUZ. Av. Augusto de Lima 1715, 30100-095 Belo Horizonte, MG.

e-mail: jcpdias@cpqrr.fiocruz.br internacionais, têm oportunizado casos novos da DCH em países não endêmicos. Na evolução da luta antichagásica no Brasil, após os trabalhos pioneiros de Emmanuel Dias e Pedreira de Freitas nos anos quarenta e cinquenta, foram priorizadas as ações químicas contra o vetor domiciliado, em especial a partir dos 1960. A melhoria habitacional nunca deslanchou como programa nacional, seja pelos altos custos, seja pela priorização do modelo desenvolvimentista urbano industrial, em detrimento de programas sociais rurais ${ }^{4}$. A partir dos anos oitenta foi implementado progressivamente o controle dos bancos de sangue, hoje cobrindo mais de $98 \%$ dos bancos no País ${ }^{4,5}$.

As demais formas de transmissão não foram consideradas para programas governamentais no Brasil, embora estudadas em sua ocorrência e pesquisadas algumas possibilidades de controle. Nesta pequena revisão, se pretendem discutir a importância e as perspectivas de prevenção dessas modalidades alternativas e da via congênita, no contexto dos achados e desdobramentos do II Inquérito Nacional de Prevalência, recém-terminado. 


\section{Transmissão congênita ou vertical}

Conforme o Consenso Brasileiro em Doença de Chagas $(\mathrm{CBDC})^{1}$ e o Colóquio Internacional sobre infecção congênita na Bolívia $^{6}$, ambos publicados em 2005, e uma revisão de Altrech, em $2008^{7}$, a ocorrência de transmissão congênita ou vertical (TC) é variável nas áreas endêmicas, dependente basicamente do número de gestantes infectadas pelo Trypanosoma cruzi e de outros fatores ainda não bem conhecidos.

Em nosso País, o risco de TC em gestantes infectadas oscila em torno de $1 \%$, ampliando-se esta proporção para $4 \%$ e até $12 \%$, em outras áreas latino-americanas ${ }^{6}$. Sua incidência tende francamente à redução nas áreas de controle vetorial e transfusional implementados, pela redução progressiva da prevalência da infecção chagásica entre mulheres de idade fértil. Por exemplo, dados bem controlados em Bambuí/MG, mostravam prevalência acima de 30\% das mulheres na década de 1950, baixando para $9 \%$ nos anos setenta e para menos de $1 \%$ em $2006^{8}$.

Dados para Minas Gerais, em 2004, mostraram 1\% de infecção entre 65.000 puérperas examinadas ${ }^{9}$. Em paralelo, o corrente inquérito Nacional entre menores de cinco anos, com mais de 100.000 amostras colhidas no Brasil, está demonstrando uma taxa de infecção infantil abaixo de 0,02\% com taxas de TC aparentemente mais expressivas no Rio Grande do Sul (dados preliminares).

A definição de caso congênito, conforme o CBDC, considera basicamente as crianças nascidas de mães infectadas, com a confirmação do parasita no sangue do recém nascido e/ou a detecção de anticorpos não-maternos na criança após os 6 ou 7 meses de idade, desde que excluídos outros mecanismos de transmissão ${ }^{1,10,11}$.

Clinicamente, a experiência acumulada nos diversos estudos mostra que mais de $70 \%$ das crianças com TC são normais e assintomáticas. Um resíduo nunca maior que $10 \%$ apresentará clínica florida e potencialmente grave, com quadro febril, hepato-esplenomegalia, miocardite, meningo-encefalite ou prematuridade ${ }^{7,11}$. Esses casos têm especial importância pelo risco concreto de morte, devendo ser prontamente diagnosticados e tratados. Para tanto, há consenso que frente a tais quadros em recém-nascidos, os pediatras pensem em doença de Chagas, em áreas endêmicas, assim como diante de mães com antecedentes ou clínica sugestivos de infecção. Quanto ao diagnóstico, as melhores experiências em pesquisa direta do parasita têm sido através do método de microhematócrito. Reação em cadeia da polimerase (PCR), xenodiagnóstico e hemocultura, quando disponíveis, têm boa sensibilidade, mas não significam definitivamente infecção aguda nem transmissão congênita ${ }^{10,12}$. É consenso de que a DCH congênita é muito vulnerável ao tratamento específico com as drogas hoje disponíveis (nifurtimox e benzonidazol) com cura acima de $90 \%$ dos tratados e com mínimos efeitos colaterais. Pacientes tratados e seguidos por muitos anos mostraram boa resposta terapêutica e nenhuma sequela clínica ou imunológica da infecção, a longo prazo ${ }^{10,11}$.

O diagnóstico da DCH congênita se faz por métodos parasitológicos e sorológicos como entendido no conceito acima de definição de caso. Na circunstância de suspeita clínica forte em recém-nascidos de mulher infectada, recomendase insistir na busca direta do parasita, repetindo os exames várias vezes ao dia, em dias seguidos. Emprega-se também métodos parasitológicos indiretos, como hemocultura e xenodiagnóstico. Também se sugere a $\mathrm{PCR}^{6,10,12}$.

A prevenção da DCH congênita se resume na detecção do caso e seu tratamento específico, o mis precocemente possível. Idealmente, o melhor é começar ainda na gravidez, através de sorologia em gestantes com suspeita clínica ou epidemiológica. Os recém-nascidos das mães infectadas seriam pesquisados ao nascer com exames parasitológicos, tratando-se imediatamente os que resultassem positivos. Sendo negativos parasitologicamente, fazer sorologia convencional aos 7 ou 8 meses de vida (quando desaparecem os anticorpos IgG maternos), tratando imediatamente os que forem positivos. Em alguns países como Uruguai, Paraguai e partes da Argentina, há screening sorológico de gestantes de rotina em pré-natal. No Brasil, não há este procedimento como programa nacional, embora entidades como a APAE o realizem em Mato Grosso do Sul e Goiás. Em Minas Gerais, foram feitas duas investigações estaduais mediante sorologia para DCH no conhecido teste do pezinho, mostrando viabilidade técnica e exequibilidade. Nesta experiência, as crianças soropositivas foram re-estudadas aos sete meses de vida, revelando mínima incidência de TC e sendo tratadas aquelas poucas que permaneceram positivas. Simplificando mais ainda, apenas o exame sorológico convencional aos sete meses de idade já seria altamente oportuno em áreas endêmicas e/ou situações de suspeição clínica e epidemiológica ${ }^{2,3,10,12}$. Nesta estratégia, os casos de maior suspeição clínica, ao nascer, seriam, apenas estes, examinados exaustivamente por técnicas parasitológicas, acrescentando-se PCR e - se disponível sorologia com antígeno SAPA, que marca mais precocemente a transmissão congênita. Em negativos, persistindo a dúvida, o tratamento específico de prova pode ser considerado ${ }^{3,10,12}$.

\section{Transmissão acidental do Trypanosoma cruzi ao homem}

Na década de 1980, o Prof. Zigman Brener (1984) já havia contabilizado mais de cinquenta episódios, numa listagem pessoal informada por vários serviços no Brasil e Exterior. Julgava-se que eram muitos mais, pois o evento pode ocorrer nas mais variadas circunstâncias e muitas vezes passam desapercebidos ou não-diagnosticados. Por outro lado, geralmente não há interesse em sua divulgação, pelo fato de significar insegurança, desaparelhamento ou inaptidão técnica do serviço ou pesquisador em questão ${ }^{2,13-16}$. Por outro lado, compreensivelmente, também o próprio acidentado soe ocultar ou negar a ocorrência do acidente, assim como é bastante comum uma fase aguda clinicamente pouco expressiva ou mesmo inaparente, problematizando a suspeição clínica e o próprio diagnóstico ${ }^{2}$. Os acidentes têm ocorrido nas mais diversas situações, seja em laboratórios de triatomíneos, seja na captura do vetor em áreas endêmicas, ou em trabalhos experimentais com mamíferos infectados e culturas, ou em aerossóis de materiais infectados. Também há relatos de contaminação cirúrgica a partir de pacientes agudos, coleta de sangue nesses casos, deficiências de segurança no transporte de materiais infectados etc ${ }^{2,13,14}$. Os fatores de risco passam por desconhecimento, desatenção, falta ou mal uso de equipamentos de proteção individual, instalações e equipamentos inadequados, iluminação deficiente, falta de capacitação etc ${ }^{2,3}$. 
A prevenção desta via de transmissão passa por uma instância primária (antes da ocorrência) e outra secundária (prevenção do dano após o fato acontecido). Como não existe vacina, um estratagema usado por alguns chefes de pesquisa tem sido, quando possível, empregar e treinar técnicos já infectados pelo T. cruzi. Em caráter ainda primário, é fundamental configurar-se adequada e rigorosamente o ambiente de trabalho com o parasita, assim como dispor de equipamentos de trabalho e proteção individual (luvas, máscara, óculos, mangas largas) adequados. Treinamento rigoroso de pessoal é indispensável, seja para técnicos, seja para iniciantes em pesquisa. É muito pertinente que todo técnico a ser envolvido com o parasita faça um teste sorológico ao começo de sua atividade, para oportunas comparações, em eventuais acidentes pois, por muitas vezes, o diagnóstico de fase aguda só se locupleta mediante viragem sorológica ${ }^{2,14,17}$.

A prevenção secundária a presenta caráter bastante prático e bem consensuado. Ocorrido um evento com suspeita de transmissão, uma série de providências deve ser desencadeada: a) se houve ferimento ou contaminação (externa ou ocular), proceder à pronta desinfecção local com álcool, mertiolate ou nitrato de prata; b) colher sorologia de controle; c) iniciar prontamente tratamento específico com benzonidazol ou nifurtimox nas doses habituais, por dez dias. Após um mês, repetir a sorologia convencional. Se o primeiro exame foi negativo e este positivo, considerar que houve transmissão e reiniciar o tratamento específico, agora em sessenta dias. Segundo o Consenso Brasileiro ${ }^{1}$, acidentes com alta carga parasitária devem ser tratados por um período mínimo de trinta dias. Em situações de mínimo risco, como, por exemplo, com sangue de paciente crônico, a profilaxia medicamentosa não está indicada, recomendando-se o monitoramento sorológico.

Todo acidente e/ou ocorrência de transmissão acidental deve ser comunicado a uma comissão interna de bio-segurança e às Autoridades Sanitárias, assim ensejando investigação do caso e avaliação/correção dos fatores de risco ${ }^{2,10,14,17}$.

\section{Transmissão por transplantes de órgãos}

Quando considerada a infecção pelo T. cruzi, no contexto dos transplantes de órgãos, duas situações devem ser levadas em conta. Pode haver transmissão a partir do doador chagásico ou é viável reativação da parasitemia se o receptor está previamente infectado. A veiculação do parasita de doador infectado já foi documentada em transplantes de coração, fígado, medula óssea, pâncreas ou rim, a partir de doador vivo, com morte cerebral, eventualmente de cadáver ${ }^{2,3}$. Os primeiros relatos de ocorrência de transmissão da doença de Chagas datam do início da década de 1980, especialmente através de transplante de rins ${ }^{18}$.

A conduta básica a ser considerada nesta modalidade de transmissão tem por princípio o diagnóstico da infecção no doador e no receptor, através de sorologia convencional bem conduzida e realizada com duas técnicas diferentes, de alta sensibilidade e especificidade. O transplante de órgãos geralmente é procedimento prioritário como intervenção médica, cabendo judiciosa avaliação de sua realização, tanto em caso de doador como de receptor infectado. O ideal é não realizá-lo na situação de doador infectado e receptor suscetível, porém, via de regra, isto é difícil por questões de emergência clínica, de histocompatibilidade e disponibilidade de órgãos. Semelhantemente, a necessidade de um transplante para receptor infectado geralmente é razão mais forte que o risco ou consequências de reativação no pós-operatório ${ }^{3,18}$.

Assim, consideradas as diferentes combinações de infecção e suscetibilidade, os aspectos de prevenção da doença de Chagas, frente ao transplante de órgãos, poderiam resumir-se, após sorologia convencional pré-cirúrgica, $\mathrm{em}^{2,3,10,19}: 1$ ) doador negativo e receptor negativo: nada a fazer quanto a DCH; 2) doador negativo e receptor positivo: basicamente atenção médico-laboratorial ao receptor no pós operatório para detecção de eventual reativação devida a imunossupressão. Em ocorrendo, tratar o paciente como agudo, assim minimizando os riscos de cardite aguda e/ou meningoencefalite; 3 ) doador positivo e receptor positivo: agir como na alternativa descrita no item 2 ; 4) doador positivo e receptor negativo: é o caso mais importante, de ocorrência relativamente freqüente, em particular nos transplantes renais. Geralmente, a necessidade do transplante é de motivação prioritária e o ato cirúrgico deve ser realizado, não se descartando o doador. Assim, indicada a cirurgia, e de acordo com a experiência existente, há duas alternativas: a) pode-se tratar o doador com imidazólico por dez dias prévios à operação (para baixar sua parasitemia), tratando-se profilaticamente o receptor nos dez dias subsequentes à mesma, para prevenir a instalação do parasita ${ }^{3}$; b) pode-se monitorar o receptor clínica, parasitológica (hemocultivos, exames diretos) e sorologicamente (sorologia aos 15 e 30 dias), iniciando o tratamento específico se houver parasitemia detectável ou conversão sorológica².

\section{Transmissão oral e por leite materno}

A transmissão da doença de Chagas por via oral é considerada como mecanismo primário, mormente no ciclo silvestre da tripanossomíase americana. No Brasil, já fora aventada desde os anos 1920, através de modelos experimentais, sendo identificados os primeiros casos de grande probabilidade na década de 1960, no Rio Grande do Sul. Posteriormente, surtos muito prováveis de transmissão oral foram detectados, no Pará, na Paraíba, em outras áreas amazônicas, em Santa Catarina, na Bahia e no Ceará. Em outros países, houve surtos no México e na Venezuela, mais recentemente ${ }^{2,3,10}$. Vários estudos experimentais demonstraram a viabilidade da transmissão oral em vários modelos animais ${ }^{14}$.

As seguintes possibilidades devem ser aventadas em relação ao mecanismo de transmissão oral na doença de Chagas ${ }^{2,3}: 1$ ) ingestão de leite materno, de mãe infectada (o parasita pode vir da própria glândula ou contaminar o leite em casos de sangramento mamilar); 2) ingestão de sangue de mamífero infectado; 3 ) ingestão de carne mal cozida de mamífero infectado, especialmente reservatórios silvestres; 4) ingestão de suspensão de T. cruzi em pipetas (acidente de laboratório); 5) ingestão de alimentos ou bebidas contaminados com fezes ou urina de triatomíneos infectados por T. cruzi; 6) ingestão de alimentos ou bebidas contaminados com urina ou secreção para-anal de marsupiais infectados por T. cruzi. 
O quadro clínico é variado, sem lesões de porta de entrada, ocorrendo febre, fenômenos de irritação gástrica, dores abdominais, vômitos, melenas e icterícia em muitos casos. Sobrevêm com o tempo, em casos mais graves, cardiopatia aguda e sinais de irritação meníngea. A letalidade nos casos amazônicos (os mais numerosos) pode chegar a $5 \%$. Diferentemente da via vetorial, os casos até aqui detectados estão em todos os grupos etários, indiscriminadamente. $\mathrm{Na}$ suspeita transmissão oral, hão que descartar-se os mecanismos vetorial, congênito, transfusional/transplante e acidental. Mais da metade dos casos contabilizados apresenta a característica de surtos familiares ou comunitários, com adoecimento em dias próximos e uma causa comum referente a um evento alimentar, num mesmo lugar ${ }^{1,2,3}$. 0 tratamento é o clássico da forma aguda, cuidando-se adicionalmente de possíveis hemorragias digestivas.

A prevenção da transmissão oral é relativamente difícil, dado o caráter aleatório e inesperado de seu acontecimento. Medidas gerais de higiene e boa seleção alimentar se impõe, assim como a boa cocção de carnes silvestres de áreas endêmicas. No caso de alimentos produzidos artesanalmente, em áreas com triatomíneos, normas de boa cocção e/ou pasteurização se impõe. Conforme a epidemiologia desses casos nos surtos investigados, a ocorrência de outros casos na sequência de um primeiro (índice) é bastante frequente. Assim, a busca ativa de contatos se impõe, para delimitação do surto e oportunização de tratamento específico ${ }^{3}$.

No caso do leite materno, há que cuidar-se para que este assunto não seja propalado indevidamente, provocando resistência das mães em amamentar. Sua ocorrência é verdadeiramente excepcional, e os pouquíssimos casos suspeitados envolveram mulheres com sangramento mamilar. Assim, sugere-se desaconselhar por algum tempo a amamentação apenas em mulheres em fase aguda ou estado de reativação da esquizotripanose (alta parasitemia) ou infectadas crônicas que apresentem rachaduras ou sangramento nos mamilos e aréolas ${ }^{3,10}$.

\section{Outras situações excepcionais de transmissão}

$\mathrm{Na}$ história da evolução dos conhecimentos sobre a DCH, várias hipóteses ou possibilidades de transmissão têm sido aventadas, todas de ocorrência improvável e caráter excepcional ${ }^{2,4,14}$. Nessas hipóteses, envolvem-se situações incomuns como vetores alternativos, comportamentos humanos esdrúxulos e circunstâncias excepcionais de localização do parasita, várias delas com respaldo experimental. Como denominador comum, estará quase sempre uma grande concentração do parasita no ambiente de ocorrência, no mais das vezes envolvendo o triatomíneo vetor e/ou uma alta parasitemia em humanos ou reservatórios ${ }^{2}$, fatos esses que podem orientar eventuais ações preventivas. Conforme revisões anteriores, poder-se-ia apontar ${ }^{2,3}: 1$ ) Transmissão pela picada de um triatomíneo. Aventada pelo próprio Chagas, inicialmente. Não há colonização das glândulas salivares do vetor, pelo parasita. Ocorreria de maneira excepcional se houver regurgitação de conteúdo estomacal do inseto contaminado, durante a picada, ou se a probóscida do vetor estiver contaminada por fezes infectadas dele mesmo ou de outro vetor. A prevenção lógica é a eliminação de triatomíneos no âmbito domiciliar, por via química e ordenamento do ambiente. 2) Contato do indivíduo suscetível com fezes contaminadas de triatomíneos. Situação plausível em acidentes de laboratório, capturas de triatomíneos e contatos com paredes, objetos ou anexos domiciliares de vivendas infestadas, onde abundam dejeções do inseto, mormente em casos de elevada infestação. A permanência do parasita nessas fezes é viável por algum tempo (geralmente minutos), enquanto não ressecam. A transmissão dependerá do contato com mucosas íntegras ou pele lesada do suscetível. A prevenção também é pelo controle do vetor em unidades domiciliares, higiene ambiental e pronta desinfecção do local de contato, quando apercebido. Para capturas e manejo do vetor, indicados cuidados e equipamentos de proteção individual (ver item 2). 3) Picada ou contato com outros artrópodes. Semelhantemente ao caso da picada de triatomíneos, basicamente envolvendo espécies hematófagas de insetos (culicíneos, flebotomíneos, cimicídeos, pulgas e piolhos), ou vários carrapatos, em situações raras, mas comprovadas experimentalmente ${ }^{2,14,15}$. Os mecanismos básicos envolveriam regurgitação após contaminação prévia em indivíduo com parasitemia alta, contaminação de probóscida e esmagamento ou ingestão de um artrópode destes, precariamente infectado pelo T. cruzi. Em todos eles, o parasita pode permanecer algum tempo (horas) no segmento digestivo proximal, sem desenvolver seu ciclo natural. Em caso de moscas e baratas, tais insetos seriam apenas carreadores muito eventuais de fezes contaminadas de triatomíneos, em ambientes infestados, oportunizando transmissão oral ou por contato. A lógica da prevenção passa naturalmente pelo controle triatomínico, pela higiene ambiental e pela desinsetização de quartos onde houver um caso agudo (ou reativado) de doença de Chagas. 4) Transmissão através de secreção de glândulas anais de marsupiais. Assunto primeiramente estudado por Deane e $\operatorname{col}^{20}$, no Brasil, em Didelphis albiventris ou marsupialis (gambá). Em áreas endêmicas brasileiras, este marsupial sinantrópico se mostra sempre com altas taxas de infecção natural (média de $30 \%$ ), sendo que dos infectados sistemicamente pelo menos $5 \%$ apresentam o parasita em suas glândulas anais ${ }^{2,20}$.

O material destas glândulas pode ser expelido pelo gambá e contaminar alimentos ou diretamente um mamífero suscetível. Reproduzido com facilidade em laboratório, este mecanismo pode ter sido a causa do surto de DCH em Teutônia/ RS, nos anos $1960^{2,14}$. De difícil ocorrência, a prevenção desta modalidade envolve o afastamento de gambás dos ecótopos artificiais, assim como nos cuidados no manejo desses animais. Acontecido o contato com a secreção, monitorar o paciente (sorológica e parasitologicamente), entrando com tratamento específico concomitante se o gambá estiver muito parasitado e se o contato com o material contaminante for em mucosas ou pele lesada. De qualquer forma, realizar generosa desinfecção local, com álcool iodado ou solução similar. 5) Transmissão por via sexual. Trata-se de possibilidade remota, tendo sido conseguida experimentalmente: coito de cadelas com vagina inseminada com tripomastigotas, contaminando machos suscetíveis e infecção de cadelas e roedores suscetíveis por via vaginal com sêmen infectado. No ser humano há suspeita de contaminação de varões suscetíveis pelo coito com mulheres 
infectadas, durante menstruação $0^{2,10,15}$. Essas possibilidades aumentam muito a partir de indivíduos com alta parasitemia (agudos ou imunossuprimidos), devendo-se recomendar abstinência sexual para os mesmos ${ }^{2}$.6) Outras possibilidades hipotéticas e ainda mais remotas; praticamente restritas a indivíduos de alta parasitemia. Trata-se de situações nunca comprovadas, imagináveis apenas em que sangue ou secreções contaminados poderiam entrar em contato com suscetíveis, por exemplo, através do uso comum de seringas e agulhas descartáveis, ou em juras de amor com trocas de sangue, ou rituais macabros etc ${ }^{2}$.

Em síntese, os principais cuidados pertinentes aos mecanismos menos usuais de transmissão dizem respeito ao combate sistemático de triatomíneos e outros insetos no intradomicílio, ao afastamento e cuidados no manejo de gambás e outros reservatórios, ao redobrado cuidado e tratamento específico imediato de indivíduos com alta parasitemia, à boa higiene alimentar e ao monitoramento correto de recém nascidos de mulheres infectadas ${ }^{2,10,14}$. Na sequência do diagnóstico, será imprescindível a notificação do caso e a realização de pesquisas que confirmem a via de contaminação e a eventual ocorrência de transmissão para outras pessoas ${ }^{1,16}$.

\section{REFERÊNCIAS}

1. Ministério da Saúde. Consenso Brasileiro em Doença de Chagas. Rev Soc Bras Med Trop 2005; 38 (supl III):29.

2. Chieffi PP, Amato Neto V. Prevenção referente às modalidades alternativas de transmissão do Trypanosoma cruzi. São Paulo: CLB Balieiro Editores; 2000.

3. Dias JCP, Macêdo VO. Doença de Chagas 2005. In: Coura JR, editor. Dinâmica das doenças infecciosas e parasitárias. Rio de Janeiro: Guanabara Koogan; p. 557-594.

4. Dias JCP, Schofield CJ. The evolution of Chagas Disease (American Trypanosomiasis) control after 90 years since Carlos Chagas discovery. Mem Inst Oswaldo Cruz 1999; 94 (supl I):103-122.

5. Dias JCP. O controle da doença de Chagas no Brasil. In: Silveira AC, editor. El control de la enfermedad de Chagas en los países del Cono Sur de América Historia de una iniciativa internacional. 1991/2001. Uberaba: OPS, Faculdade de Medicina do Triângulo Mineiro; 2002. p. 146-250.

6. Colóquio Internacional. Infección congenita por Trypanosoma cruzi: desde los mecanismos de transmisión hasta una estrategia de diagnóstico y control. Cochabamba, Bolivia, 6-8 Noviembre de 2002. Rev Soc Bras Med Trop 2005; 38 (supl II):128.

7. Altrech J. Chagas pediatric and congenital. In: Proceedings of the Symposium "Chagas Disease a Public Health Threat in the Americas and Beyond” Annnecy, FR: Fondation Merieux; 2008.

8. Dias JCP. História Natural da Doença de Chagas [monografia]: Belo Horizonte: Academia Mineira de Medicina; 2006.

9. Gontijo ED, Dias JCP, Januario JN. Inquérito Sorológico da Transmissão Vertical da Doença de Chagas em Minas Gerais. Seminário Eletrônico em 23 de junho de 2007. Belo Horizonte: (versão preliminar em CD ROM, UFMG), Universidade Federal de Minas Gerais: 2007.

10. Carlier Y, Dias JCP, Luquetti AO, Hontebeyrie M, Torrico F, Truyens C, Trypanosomiase américaine ou maladie de Chagas. Enciclopédie MédicoChirurgicale 2002; 8: 505-A20.

11. Moya P, Moretti E. Doença de Chagas Congênita. In: Dias JCP, Coura JR, editores. Clínica e terapêutica da doença de Chagas. Uma abordagem prática para o clínico Geral. Rio de Janeiro: FIOCRUZ Editora; 1997. p. 383-410.

12. Luquetti AO, Rassi A. Diagnóstico laboratorial da infecção pelo Trypanosoma cruzi. In: Brener Z, Andrade ZA, Barral-Neto M, editores. Trypanosoma cruzi e doença de Chagas $2^{\mathrm{a}}$ ed. Rio de Janeiro: Guanabara Koogan Editora; 2000. p. 345-378.

13. Brener Z. Laboratory aquired Chagas' disease:endemic among parasitologists? In: Morel CM, editor. Genes and Antigens of Parasites, a Laboratory Manual. Second Edition. Rio de Janeiro: Fundação Oswaldo Cruz; 1984. p. 3-9.

14. Dias JCP. Mecanismos de transmissão. In: Brener Z, Andrade ZA, BarralNeto M, editores. Trypanosoma cruzi e doença de Chagas. Rio de Janeiro: Guanabara Koogan; 1979. p. 152-174.

15. Miles MA, Yeo M, Gaunt MW. Epidemiology of American Trypanosomiasis. In: Maudlin I, Holmes PH, Miles MA, editores. The Trypanosomes, London: CABI Publishing; 2004. p. 243-251

16. World Health Organization. Control of Chagas Disease. Second report of the WHO Expert Committee (WHO Technical Report Séries 905). Geneva: WHO; 2002

17. Brener Z, Alquezar AS, Luquetti A. Normas de segurança para infecções acidentais com o Trypanosoma cruzi, agente causador da doença de Chagas. Rev Patol Trop 1997; 26:129-130.

18. Chocair PR, Sabbaga E, Amato Neto V, Shiroma M, Góes GM. Transplante de rim: nova modalidade de transmissão da doença de Chagas. Rev Inst Med Trop São Paulo 1981; 23:280-292.

19. Ferreira MS, Nishioka CA, Rocha A, Silva AM. Doença de Chagas e imunossupressão. In: Dias JCP, Coura JR, editores. Clínica e terapêutica da doença de Chagas. Uma abordagem prática para o clínico Geral. Rio de Janeiro: FIOCRUZ Editora; 1997. p. 365-382.

20. Deane MP, Lenzi HL, Jansen AM. Trypanosoma cruzi vertebrate and invertebrate cycles in the same mammal host, the opossum Didelphis marsupialis. Mem Inst Oswaldo Cruz 1984; 79: 513-515. 